\title{
Unsolved questions and preferred solution about living will
}

\author{
Antonina Argo, Tommaso D'Anna, Antonietta Lanzarone and Luciano Sesta ${ }^{*}$
}

\begin{abstract}
Background: Ethical problems about end-of-life medicine include a variety of issues approached in different ways by physicians and, more recently, special emphasis to this kind of ethical issues and possible answers has done by Italian National Ethical Committee in the issue named "Deep and continuous palliative sedation in the imminence of Death" (January, 2016). The debate is very critical in Intensive Care Units and Cancer Wards, where health care professionals face-off with terminally-ill patients is an outright routine; the Authors investigated their medical knowledge and ethical perception about patient critical and terminal condition to discuss the most relevant conclusions.

Material: In the Sicilian province of Palermo, physicians working in Intensive Care and Oncology fields were been given a questionnaire that takes inspiration from the Ethicatt Questionnaire-Doctor. The authors reported the results obtained, by selecting and analyzing the most involved questions about living wills.

Results: Generally, the respondents showed a great sensibility on this topic. Overall agreement on the living will was observed, as past surveys, but also a new conception. Euthanasia remains not very popular, attitude in line with other countries. Opinions and aptitudes of relatives have minor importance towards patient's wishes, that are in some cases in first place.

Conclusion: Explicit positive answer towards dilemmas about living wills lifts the veil and reveals how these ones would represent a very useful tool for health care professionals in this study. It is also plausible that, if doctors had available an advance directive (living will) document, they would follow it, overcoming any contingent ethical objections.
\end{abstract}

Keywords: Living wills, Personal autonomy, End of life care, Advance directives, Questionnaire, Critical care, Resuscitation

\section{Background}

Existing dilemmas concerning end-of-life medicine - as issues about patient informed consent for life-saving treatments, or attitudes of medical professionals towards decision-making about do not start or suspend lifesustaining/prolonging care - today more than ever are becoming crucial (Müller-Busch et al., 2004), especially whereas the comparison is between doctors and critical/ terminally-ill/unconsciousness patients, as at Intensive Care Units (ICUs) and Cancer Wards, where this opposition may be an outright routine. Consequently, it is needed, as observed by many medical and societies associations, to intervene in this matter, as exemplified by the guidelines of Italian Society for Anesthesia, Analgesia, Resuscitation, and

\footnotetext{
* Correspondence: Iuciano.sesta@unipa.it

Department For Health Promotion, Maternal and Child care, Legal Medicine Section, "Paolo Giaccone" Polyclinic University Hospital, Via del Vespro 129, 90127 Palermo, Italy
}

Intensive Care (SIAARTI) for admission to and discharge from Intensive Care Units, and the limitation of treatment in Intensive Care (Gruppo di Studio ad Hoc della Commissione di Bioetica della SIAARTI, 2003).

We have thus deemed necessary to investigate this matter, on the wake of other studies carried out in the last decade (Cecchi et al., 2006; Molloy et al., 2016), about attitudes and thoughts of physicians concerning patients' rights to choose the best care for themselves and, therefore, the importance assigned to the consent of patient and how he was able to address the question in the incompetent patients. We also considered significant opinions of physicians towards life-saving treatments in the case of terminally or dying patients, when deep sedation could be necessary. 


\section{Materials and methods}

This study was realized by using a survey based on the more well-known Ethicatt Questionnaire-Doctor. This is a questionnaire established in the context of a larger study approved by the European Commission under the 5th Framework Programme for funding the research, carried out in Italy by the Faculty of Sociology, University of Rome "La Sapienza", and the International Forum of the Institute of Biophilosophy of Louvain (Cecchi et al., 2006; Molloy et al., 2016).

We slightly modified that questionnaire, in considerations of changing of social and medical background in recent years. Our one (Additional file 1) consists in 30 queries, each query is composed of one or more items, and each item provides as possible answers yes, no, or I don't know. The answer was anonymous, but we asked about age and years of work experience: this data would allow to relate our research variables with the view expressed by respondents.

The aim of our study was to examine mainly the views and opinions of physicians - but also their attitudes about ethical end-of-life issues, with particular reference to living wills and its facets. The target of our analysis was therefore based on clinical judgment on dilemmas such as the suspension or the decision not to start a lifesaving treatment, the consent of the patient and family, goals of targeted therapies in terminally-ill patients and, lastly, the behaviour the doctors would assume if themselves were the patients.

In order to provide a satisfactory reliability to results, we administered the survey to physicians who, in our opinion, more frequently face the realities raised in it. We therefore selected physicians in the field of intensive care (anesthetists, coronaric intensive care health care professionals) and oncology. Upon delivery, it was decided to detailed presentation and explanation of the survey and its questions. The survey was administered from September 5th to 14th, 2011, to doctors working in the city and the province of Palermo, Italy. All over 89 of them have completed it. Statistical analysis was performed by using with IBM SPSS Statistics v20.

\section{Results}

Given the complexity and variety of topics in the questionnaire, we considered worthwhile making a choice between them, tackling the various issues individually and first analyzing questions related to problem of the patient's consent and topics related to living wills. The first three questions we analyse regard the opinion of the physician about people to involve in the decisionmaking process (Questionnaire, items 1-3).

Interestingly, the vast majority of our sample discusses with other doctors regarding the refusal or withdrawal of life-saving treatments (86.5\%), with healthcare assistants involvement in more than one third of cases (36\%), while very few of them prefer to decide on their own (13.5\%).

All the respondents also agreed that the decision on life-saving treatments in terminally-ill should be involved the competent patient (100\%) and, for a good part of respondents, even the family of incompetent patients (86.5\%). However, only three-quarters of them continue to be like mind with regard to information of patient when this reach the end of life (75.3\%), and in almost half of cases it is preferred to inform the family but not the patient (43.5\%), with an almost total makeshift on family in case of competent patients (95.5\%).

These data highlight a difficulty of the physician to face with the patient dilemmas related to end of life. In fact, while it is true that, in case of terminally-ill patients, consent to life-saving treatments can be practically taken for granted (100\%), the approach is less obvious when it needs to inform the patient at end of life (because dying), falling back on family (43.8\%), as if he were deemed unable to face its relationship with death (Fig. 1).

Equally noteworthy are the results of the following three questions (Questionnaire, items 4-6), that concern the physician's opinion towards the relationship between informed consent and life-saving treatments (Fig. 2).

Specifically, firstly we noted that, in case of interruption of life-saving treatments, about half of our sample prefers a valid written consent $(51.7 \%)$ to an oral one (28.1\%), while just over a doctor in ten decides not to acquire any consent $(11.2 \%)$, and a similar number of them prefers not to document the event in the medical record (13.5\%). Then we can observe that in deciding to start life-saving treatment on a competent patient, the clinical condition is crucial (100\%), followed by opinion of the patient (86.5\%) and the wish of doctors (64\%), while is tended to give less importance to the opinion of other doctors and healthcare assistants (39.3\%), and least of all the wish of family members $(31.5 \%$, less than one third of sample) (Fig. 3).

In the case that patient refuse care, however, the doctor tries to convince him (93.3\%), whereas a few doesn't respect his wishes (9\%). These data, when compared with similar information obtained from previous studies (Molloy et al., 2016), appear in the end, relatively in line with contemporary ethical guidelines that tend increasingly to make responsible the patient and no longer see the family as the beneficiary of information and final decision.

Then we wanted to analyse the relationship between physician and family when a decision should be adopted at the end of life of an incompetent patient. First, when it comes to decide not to start a life-saving treatment in a terminally-ill incompetent, according to the respondents, 


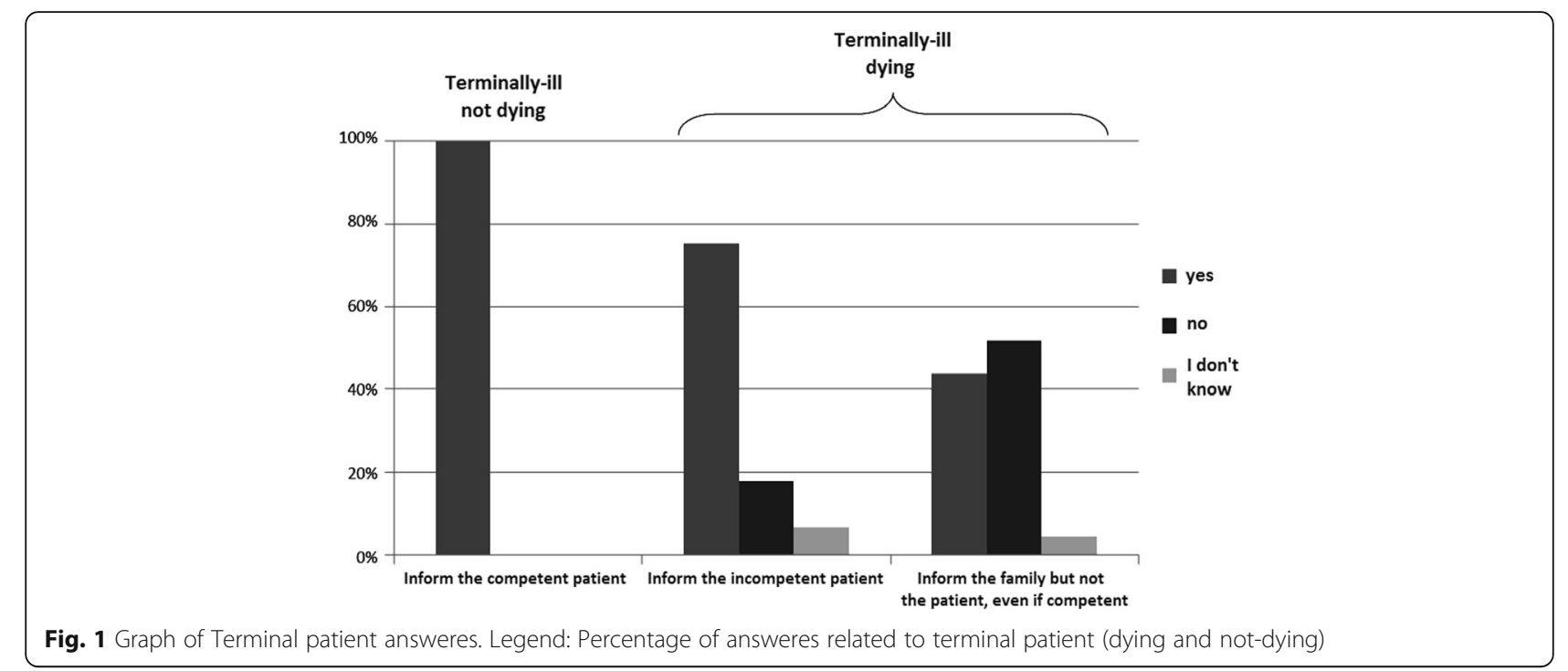

the decision is up primarily to the doctor (82\%), often in consultation with the guardian ad litem (66.3\%) and family (51.7\%). Through this question we note once again the importance of views of family members if the patient is incompetent, in agreement to what was observed in the second question.

It is interesting to note that, in deciding towards the end of life of an incompetent patient, in most cases the family is admittedly being aware of the situation and the method that will be applied (73\%), but not in all cases the doctor will meet with the family to discuss (53.9\%), and just over a third of respondents actually ask their opinion (36\%). Rather, respondents will seek to know the wishes of the patient (in $57.3 \%$ of cases requesting them to family members, $55.1 \%$ researching any written testimony).

These data show that, while in case of competent patient, opinions are quite clear in this regard, since the concerned person - in this case the patient - can express a certain opinion (note that much as 91\% of doctors sure that the patient is able to decide about end of his life, whereas few are uncertain), however, if the patient is incompetent, ideas do not seem so clear, so as to make the role of family decisive. Results of these last three examined questions are shown below (Questionnaire, items 8-10).

As stated earlier, the majority of respondents, if shall decide not to start a life-saving treatment in a terminally-ill incompetent, will seek any written record of the patient (55.1\%). This indicates that, if these doctors had available a living will, they would take it seriously, as was also emphasized in other questions (Questionnaire items 12-14).

It is immediately clear the position that physicians would take on if they had available living wills: it was observed, in fact, an explicit affirmative answer, which shows that this would be a valuable reference tool for almost all

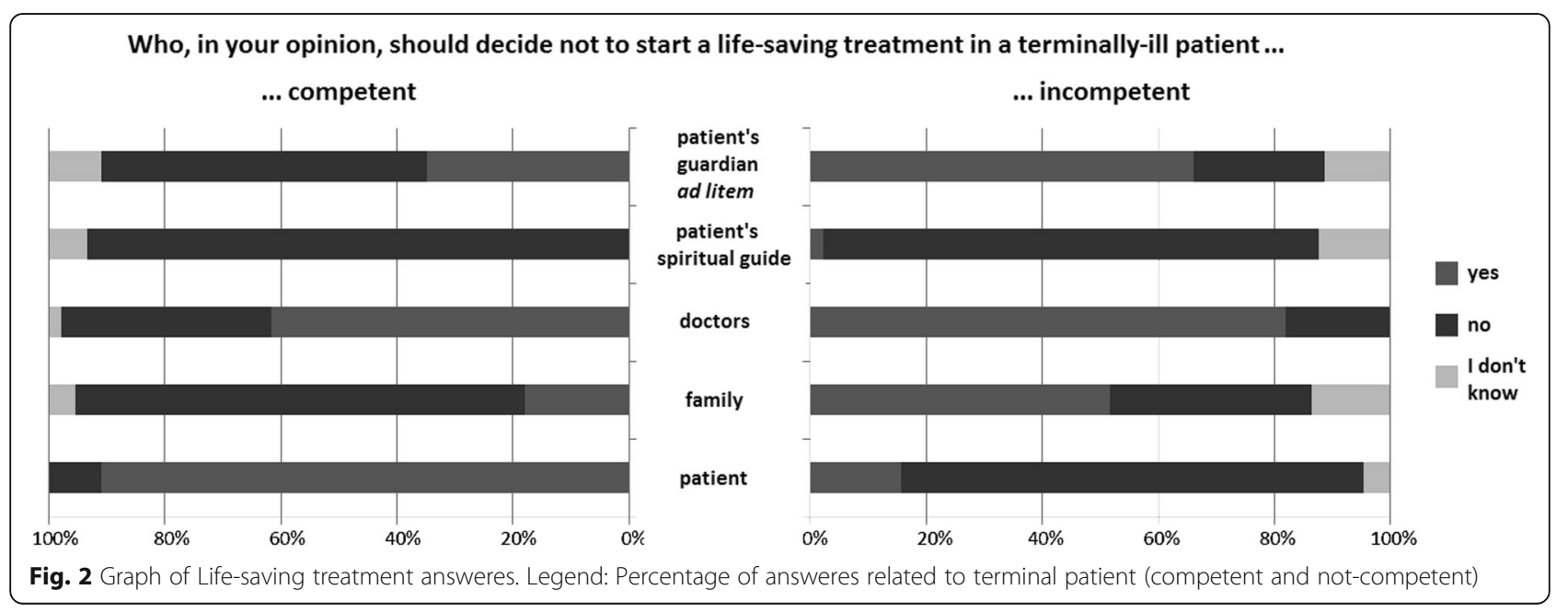




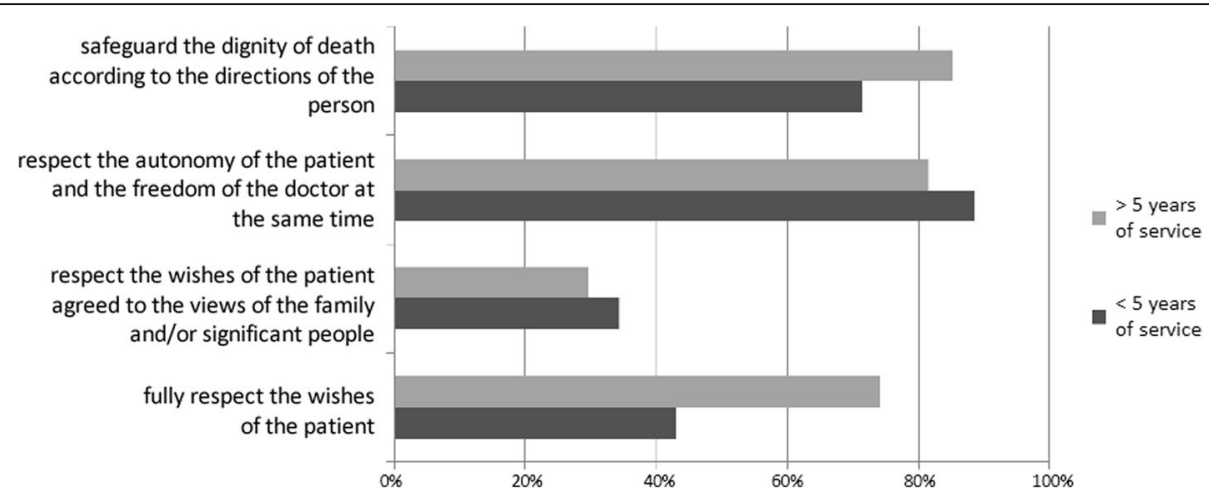

Fig. 3 Graph of Respect of willigness of the patient. Legend: Percentage of answeres related to years of service of health professionals

of them (91\%). The opinion does not seem conditioned by age or years of service. At this point the question arises: what are views on the specific issues that, conceivably, can be regarded as a possible consequence, in practice, of application of a living will.

Indeed, more than two thirds of respondents don't disdain refuse (73\%) and suspend (68.5\%) life-saving treatments in a terminally-ill patient, while only few will consider active euthanasia $(25.8 \%)$. Then the respondents, in the values scale followed during a treatment of a terminally-ill/in persistent vegetative state patient, consider as main objective the respect of patient autonomy (Baeroe K, 2010) and the freedom of the doctor in the same time (83.4\%), and many of them agree that it's important to safeguard to patient the dignity of death according to the directions of the person (79.8\%), although not all seem willing to follow its provisions - whatever they may be - to the end (61.8\%). Among the respondents with less than 5 years of service only the $42.9 \%$ considers appropriate to fully respect the wishes of the patient, whereas professionals for more than 5 years amount to $74.1 \%$. This means that doctors learn over time to accept the right of selfdetermination of the patient (Brzostek \& Zalewski, 2007), when the latter claims this one.

Should not be overlooked that, since the topic is approached for general pathways - without specifying whether the patient is dying or not - in more than half of the cases the opinions of family members or otherwise of significant people are considered secondary (58.4\%).

In the subsequent questions are analysed the opinions about objectives of end-of-life care and extreme therapies (Questionnaire items 16-18):

We can see here that respondents' opinions are examined between two determinants: quality of life and the value of the same in an incompetent patient. While we find a broad consensus that is certainly needed trying to improve, in any case, the quality of life (79.8\%), on the other hand it seems inappropriate to use this latter parameter as a yardstick to determine whether it's worth saving its integrity (only $27 \%$ of doctors would evaluate first the quality of life, and then would decide whether preserve it or not), so as to choose the second alternative - to preserve life first, and then evaluate the quality of life - preferred in more than a half of cases (55.1\%).

When taking into account that the right to refuse or suspend an intensive-care treatment in an incompetent patient, in order, our sample tends to give utmost importance to quality of life as this is seen by the point of view of patient (86.5\%), his suffering and his status (both 75.3\%), followed by chances that the patient could not survive to hospitalization (70.8\%). This attitude is in line with what emerges from deontological codes published from 1989 to present, where the quality of life and the benefit-cost ratio for patient are the reference point to discuss towards end of life (Cecchi et al., 2006; Cecchi, 2008; Koh et al., 2009). Ultimately, while with a "generic" terminally-ill patient (especially if he is competent) doctors tend primarily to comply with the wishes of the patient and preserve quality of life, facing to an incompetent patient, however, they tend to assume a "paternalistic" position, taking decisions in first person and putting in the first place the patient's life.

Extremely significant observations in this regard derives from the questions in which we investigate the wishes of physicians (Fig. 4) if they respectively were terminally-ill or unconsciousness patients (Questionnaire items 21 and 22).

The paternalistic behaviour shown in several previous questions, in this case, fails: the doctor, if he were a terminally-ill patient, absolutely would not go to Intensive Care (only $2.2 \%$ would), nor undergo artificial respiration (also only $2.2 \%$ would), while very few would undergo cardiac resuscitation if it were needed $(9 \%)$, whereas the vast majority of them would prefer to spend the last days that remain to live at home (93\%). Such attitude is consistent with the same assumed with competent patients. It should be noted that, in addition, more than a third of respondents would submit themselves even to euthanasia (37.1\%). 


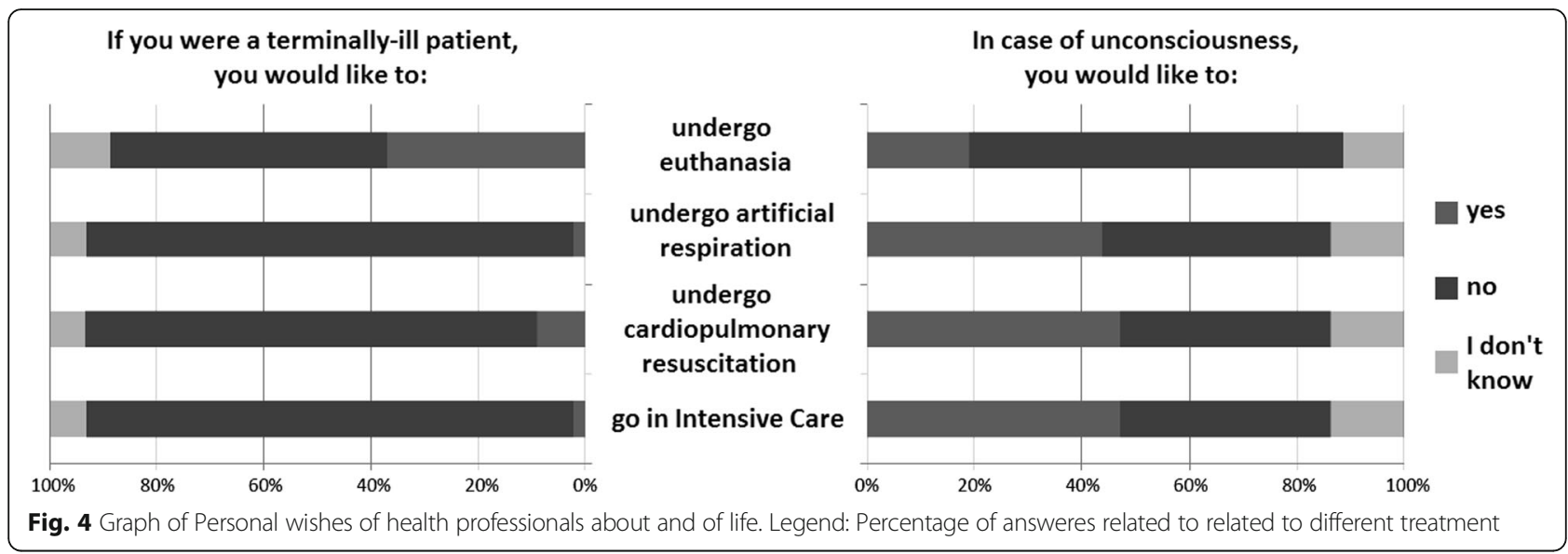

If unconsciousness, instead, the frontline is splitted in two, increasing highly the percentage of respondents who would go to Intensive Care (47.2\%) and would undergo cardiac resuscitation (47.2\%) or artificial respiration (43.8\%). The percentage of undecided also increased (13.5\%, almost a doctor out of seven): the latter date, if compared to predominance of yes towards no - that in the first three options is very modest - suggests that question has raised various doubts in respondents, probably due to the fact that the term "unconscious", in this context, takes on a somewhat vague meaning and could be interpreted as a final status as much as a temporary condition. However, even at this point the percentage of cases that would undergo euthanasia, although decreased compared to previous question, is not negligible $(19.1 \%$, almost a doctor out of five).

However, in 22nd question, results would seem be influenced by years of service: those who have worked for less than 5 years are more inclined, as opposed to those who practice longer, to be hospitalized in Intensive Care (respectively, $54.3 \%$ versus $41.8 \%$ ) and to undergo cardiac resuscitation (60\% vs $38.2 \%$ ), while opinions on artificial respiration and euthanasia are roughly comparable. Presumably, experience gained over the years achieves sort of disenchantment towards therapeutic capacity of extreme treatments.

\section{Discussion}

Dilemmas about end of life care always affect the public opinion and ingenerate different views. We found interesting focal points through the administration of our questionnaire. In decisions about beginning of life-saving therapies in a "generic" terminally-ill patient, the doctor mainly rests on the clinical condition of the patient, and only sporadically addresses to family. In an incompetent patient, instead, the doctor takes decisions in first person, even assisted by the family but especially by the guardian ad litem. This confirms, as already supported by other studies (Cecchi et al., 2006), an effective recognition from these physicians of the patient's right to express his opinion. In addition, we can appreciate that, difficulties to respect that right - when this one is in contrast with ethics of the health care professional - apparently seem overcome. These difficulties formerly gave birth to international guidelines, the Appleton Consensus (Stanley, 1989), which would seem to slowly return its fruit, though still immature (Bruinsma et al., n.d.).

Euthanasia is not very popular, attitude in line with other countries (Müller-Busch et al., 2004; Voultsos et al., 2010). With regard to family members, generally, they will simply be informed, but rarely is required their actual opinion. However, is often sought to know the wishes of the patient, that therefore, in any case, are in first place and hence it's plausible that, if the doctor had available an advance directive (living will), he would follow it (Zanone Poma S, et al., 2015), passing any contingent ethical objections (Costantini et al, 2016). This evidence is supported by several considerations:

- first, we saw that opinions of the family have been more and more considered secondary in extreme therapies, whereas according to many the real goal is the respect of patient autonomy and the freedom of the doctor in the same time (Burla C, et al.,2014);

- then, we have seen that, in dying patients, the doctor does not flaunt the same self-confidence as in the "generic" terminally-ill patient. Probably this is due to the fact that physicians often are not educated with a standardized-model medical ethics programme for the decision-making process (Fawzi, 2011). It is therefore justifiable whether the written consent towards interruption of life-saving treatments is acquired only in half of the cases, and only in two thirds of cases in the event is documented in the medical record, most likely due to a well-founded fear of contravening moral, ethical and legal precepts;

- doctors themselves, if they were terminally-ill patients, would prefer to die at home and would not 
for themselves another doctor acting in a "paternalistic" way: it's plausible that they would have advance directives;

- finally, the explicit positive answer to the question about living wills lifts the veil and reveals how these ones would represent a very useful tool for our health care professionals.

It is worthy of consideration that the crucial point of differentiation between euthanasia and un-due treatment only consists in the willingness of health care professionals at the bed of the patient (den Hartogh G, 2016), and this differentiation, consistently with indications of Italian national Committee of Bioethics, has a clearly evidence in whole recall of answers of our study.

It is important to note that our study has several limitations. First, since it was conducted in one Italian province, it may appear difficult to generalize our results. We must consider then the small sample size, that is not representative of the national attainment distribution. Furthermore, surgeons who participated in this study were not randomly selected and were aware of the purposes of this study. This may have introduced a certain degree of bias. Finally, it should be noted that this is the first use of our modified questionnaire and it have not been validated.

To conclude, we want remember that this is a pilot study and the preliminary results should be considered with caution. Our work was not intended to define general opinions and attitudes of physicians about living will, endof-life therapies and decision-making processes (Gastmans C, De Lepeleire J, 2010), but our findings may be the basis for the development of tools for obtain that goal in the future.

\section{Additional file}

Additional file 1: Questionnaire administered to health care professionals. Legend: tools and items of Questionnaire. (DOC 170 kb)

\section{Acknowledgements}

The authors wish to tank physicians who anonymously answered the questionnaire.

\section{Funding}

No funding of any form.

\section{Availability of data and materials}

The data set generating during and/or analyzed during the current study are available from the corresponding author on reasonable request.

\section{Authors' contributions}

Authors all contributed to work. Particularly: D'Anna and Lanzarone administered questionnaires and elaborated results. Sesta elaborated theorethical aspects. Argo managed questionnaire adapted version and general Project. All agreed with conclusions.

\section{Authors' information}

Antonina Argo is MD, pHD, Specialist of Forensic Medicine, Associate Professor, Accredited Pathology of American Academy of Forensic Sciences,
Deputy of Research Program for Legal Medicine, Component of Ethic Committee Policlinic Hospital University of Palermo.

Tommaso D'Anna is MD and Specialist of Forensic Medicine at University of Palermo.

Antonietta Lanzarone is MD, Resident in Forensic Medicine at University of Palermo, Sicilian Referent of National Group of Young Forensic Doctors of Italian Universities.

Luciano Sesta is Post-doc Research Fellow in Legal Medicine at University of Palermo. Specialist of Bioethics and Temporary Professor in Bioethics and

Philosophical Anthropology at University of Palermo.

\section{Ethics approval and consent to participate}

All subjects participating to this study gave their consent before answering and filling data sheet questionnaire.

Consent for publication

Not applicable, because the data are anonymous.

\section{Competing interests}

The authors declare that they have no competing interest.

\section{Publisher's Note}

Springer Nature remains neutral with regard to jurisdictional claims in published maps and institutional affiliations.

Received: 19 June 2017 Accepted: 18 December 2017

Published online: 20 January 2018

\section{References}

Baeroe K (2010) Patient autonomy, assessment of competence and surrogate decision-making: a call for reasonableness in deciding for others. Bioethics 24(number 2):87-95

Bruinsma SM, vander Heide A, vander Lee ML, Vergouwe Y, Rietjens JAC Negative impact of palliative sedation on relatives' experience of the dying phase and their wellbeing after the Patient's death: an observational study. PLoS One 11(2):e0149250. https://doi.org/10.1371/journal. pone.0149250

Brzostek T, Zalewski Z (2007) Clinical bioethics at the end of life. In: Pegoraro R, Putoto G, Wray E (eds) Hospital based bioethics. A European Perspective. Padova: Piccin, pp 95-114

Burla C, Rego G, Nunes R (2014) Alzheimer, dementia and the living will: a proposal. Med Health Care Philos 17:389-395

Cecchi R (2008) Lo stato vegetativo permanente: una questione bioetica aperta. Riv Ital Med Leg 30:973-990

Cecchi R, Di Vella G, Sannella A, Valente S, Boccardelli G, Longo E (2006) Opzioni e propensioni di un campione di medici "intensivisti" riguardo al consenso dei malati terminali circa l'attuazione e la sospensione delle cure in casi eticamente problematici (il questionario Ethicatt). Riv Ital Med Leg 28:273-286

Costantini et al (2016) Validity, reliability and responsiveness to change of the Italian palliative care outcome scale: a multicenter study of advanced cancer patient. BMC Palliative Care 15:23

den Hartogh G (2016) Continous deep sedation and homicide: an unsolved problem in law and professional morality. Med Health Care Philos 19:285-297

Fawzi MM (2011) Medical ethics educational improvement, is it needed or not?! Survey for the assessment of the needed form, methods and topics of medical ethics teaching course amongst the final years medical students Faculty of Medicine Ain Shams University (ASU), Cairo, Egypt 2010. J Forensic Legal Med 18:204-207

Gastmans C, De Lepeleire J (2010) Living to the bitter and? A personalistic approach to euthanasia in persons with severe dementia. Bioethics 24(number 2):78-86

Gruppo di Studio ad Hoc della Commissione di Bioetica della SIAARTI (2003) SIAARTI guidelines for admission to and discharge from intensive care units and for limitation of treatment in intensive care. Minerva Anestesiol 69:101-118

Koh YH, Lee OK, Wu HY (2009) "Palliative" and not "terminal" sedation. J Pain Symptom Manag 37:e6-e8

Molloy C, McCarthy J, Tyrrell M (2016) The impact of an end-of-life healthcare ethics educational intervention. Clin Ethics 11(1):28-37

Müller-Busch HC, Oduncu FS, Woskanjan S, Klaschik E (2004) Attitudes on euthanasia, physician-assisted suicide and terminal sedation-a survey of the members of the German Association for Palliative Medicine. Med Health Care Philos 7:333-339 
Stanley JM (1989) The Appleton consensus: suggested international guidelines for decisions to forego medical treatment. J Med Ethics 15:129-136

Voultsos P, Njau SN, Vlachou M (2010) The issue of euthanasia in Greece from a legal viewpoint. J Forensic Legal Med 17:131-136

Zanone Poma S, Piacentini S, Siviero F et al (2015) The opinions of GP's patients about suicide, assisted suicide, euthanasia, and suicide prevention: an Italian survey. Suicide Life Threating Behav 45(4):391-398

\section{Submit your manuscript to a SpringerOpen ${ }^{\bullet}$ journal and benefit from:}

- Convenient online submission

- Rigorous peer review

- Open access: articles freely available online

- High visibility within the field

- Retaining the copyright to your article

Submit your next manuscript at $\gg$ springeropen.com 